University of Nebraska - Lincoln

DigitalCommons@University of Nebraska - Lincoln

Papers in the Earth and Atmospheric Sciences

Earth and Atmospheric Sciences, Department

$11-2020$

\title{
Introduction to Special Section: Integrated Geophysical Imaging
}

Irina Filina

Rao Yalamanchili

Simone $\operatorname{Re}$

Daniele Colombo

Antony Price

See next page for additional authors

Follow this and additional works at: https://digitalcommons.unl.edu/geosciencefacpub

Part of the Earth Sciences Commons

This Article is brought to you for free and open access by the Earth and Atmospheric Sciences, Department of at DigitalCommons@University of Nebraska - Lincoln. It has been accepted for inclusion in Papers in the Earth and Atmospheric Sciences by an authorized administrator of DigitalCommons@University of Nebraska - Lincoln. 


\section{Authors}

Irina Filina, Rao Yalamanchili, Simone Re, Daniele Colombo, Antony Price, Vsevolod Egorov, and Guimin Liu 
Published in Interpretation 8:4 (November 2020), pp. SSi-SSv; doi: 10.1190/INT-2020-0921-SPSEINTRO.1 Copyright (C) 2020 Society of Exploration Geophysicists and American Association of Petroleum Geologists. Used by permission.

Submitted September 21, 2020; published ahead of production November 3, 2020; published online November 25, 2020.

\title{
Introduction to Special Section: Integrated Geophysical Imaging
}

\author{
Irina Filina, ${ }^{1}$ Rao Yalamanchili, ${ }^{2}$ Simone $\mathrm{Re},{ }^{3}$ Daniele Colombo, ${ }^{4}$ \\ Antony Price, ${ }^{5}$ Vsevolod Egorov, ${ }^{6}$ and Guimin Liu ${ }^{7}$
}

1. University of Nebraska-Lincoln, Lincoln, Nebraska, USA

2. Rao Geophysical Solutions, Houston, Texas, USA

3. Schlumberger, Milan, Italy

4. Saudi Aramco, Dhahran, Saudi Arabia

5. Total E\&P, Pau, France

6. GeoExpera, Houston, Texas, USA

7. BHP, Houston, Texas, USA

Corresponding author - Irina Filina, email ifilina2@unl.edu

\begin{abstract}
This special section illustrates the value of integration with nonseismic geophysical methods, namely potential fields (gravity and magnetics) and electric and electromagnetic techniques. The primary objective is to overcome the overall underappreciation of these methods as exploration tools. We provide their brief overview and present nine case studies illustrating how the integrative approach to geophysical data analysis influences the overall result and reduces the uncertainty of the derived solution.
\end{abstract}

\section{Motivation and objectives of this special section}

Integrated geophysical imaging implies a multidisciplinary comprehensive approach to subsurface model development. This infers a joint analysis of multiple geophysical data sets with all available geologic constraints that takes advantage of the strengths of each method 
while mitigating their individual weaknesses. The result of such a multiphysics study is the subsurface model that honors ALL data and constraints and remains geologically sound. The main objective of blending all of those data sets and observations together is to reduce the ambiguity of the resultant subsurface model. In addition, this integrated approach can be used to test and cross-validate geologic hypotheses such as the presence of particular formations (salt/volcanics) or subsurface conditions (overpressured sediments) that are often not well imaged in seismic cross sections. Last but not least, application of integrated analysis is developing a better regional understanding of the study area, such as deriving the overall crustal architecture, determining depth to Moho, and establishing the presence/absence of magmatic addition, etc.

This special section is inspired by the postconvention workshop after the SEG's 2018 Annual International Meeting titled "Integrated geophysical imaging" that was organized by the Gravity and Magnetics Committee (Filina et al., 2019). The workshop aimed to investigate the value of nonseismic geophysical methods, namely potential fields (gravity and magnetics), electric and electromagnetic methods, as exploration tools to characterize subsurface structures. The workshop attracted many participants from various backgrounds. Although many interesting examples were presented, the overall conclusion of the workshop was that the concept of integrated geophysical imaging is undervalued in the geoscience community. The participants unanimously agreed that the integration with nonseismic methods is often avoided due to the common misperception of their having less value because of the nonuniqueness of their solution. In fact, these methods yield a wide range of possible solutions only when they are used on their own. Once combined with other data sets and constrained with geologic information, the range of the plausible models is condensed, so they not only can reduce the overall uncertainty of the result but also can act as a gamechanger by offering an alternative, unified solution.

The lack of illustrative case studies stressing the overall benefits of the integrative analysis is one of the reasons for this common perception of nonseismic geophysical methods as unimportant. In addition, potential fields are often taught in schools as standalone techniques, while their primary strength and value are in integration with other methods. This special section aims to overcome the overall underappreciation of nonseismic geophysical methods by providing their brief overview and presenting a series of case studies illustrating how the integrative approach to geophysical data analysis influences the overall result and reduces the uncertainty of the derived solution.

\section{Typical data for integrated geophysical analysis}

The following geophysical data sets are often used for integration: seismic (reflections and refractions), potential fields (gravity and magnetics), and electromagnetic (EM) data from controlled-source EM (CSEM), transient EM (TEM), and/or magnetotelluric (MT) surveys. All these data sets represent measured variations of some physical quantity (seismic waves, gravitation acceleration, magnetic intensity, and electromagnetic signals) due to changes (i.e., contrasts) in the physical properties of subsurface rocks. Different lithologies have different physical properties, namely densities, magnetic susceptibilities, acoustic velocities, resistivity, etc. The contrast between the rocks with different lithologies generally 
results in a contrast in one or more physical properties, which can be detected by corresponding geophysical methods. For instance, the gravity field responds to density variations, the magnetic intensity "reads" the changes in magnetic susceptibilities, while the strength of seismic reflection depends on contrasts in acoustic impedance (a product of density and acoustic velocity) in the subsurface. Therefore, the same lithologic assemblage in the subsurface may be recorded by several geophysical methods. While the interpretation of one of those methods may yield a reasonable result, the output of a joint interpretation that agrees with two or more methods simultaneously increases the overall confidence and robustness of the solution.

\section{Potential fields}

The gravity and magnetic fields represent cumulative effects due to lateral variations of the density and magnetic susceptibility of the subsurface, respectively. However, not all subsurface structures will produce magnetic signals (for example the rocks that do not contain magnetic minerals). In addition, those below the Curie depth will generate zero magnetic anomalies because the rocks lose almost all their magnetic properties below those depths (Rajaram, 2007). The depth to Curie point varies dramatically between regions and can be extremely shallow (first kilometers) in the regions with a high geothermal gradient, while it is up to $45 \mathrm{~km}$ deep in cold intracratonic settings (Li et al., 2017).

There are multiple public domain sources for potential fields data. The United States Geological Survey has numerous grids primarily for the United States (e.g., Kucks, 1999; Bankey et al., 2002); the GeoMapApp has a lot of global publicly available gravity and magnetic data sets as well. The global gravity data derived from satellite altimetry are available for download from supplemental material in Sandwell et al. (2014). The global magnetic compilations of Hemant et al. (2007) and Meyer et al. (2017) are available, although the latter one is used most often.

\section{Electromagnetic data}

EM methods allow for studying variation in subsurface lithologies and/or the properties of the filling fluids based on the resistivity of subsurface rocks. CSEM is an offshore method that requires a controlled active EM source (e.g., Constable, 2010) and works in the frequency domain. Transient EM (i.e., time domain) is another active source technique widely used in shallow minerals and groundwater exploration, while MT is a frequencydomain passive method that uses solar wind as a natural source (e.g., Bedrosian, 2007) and "sferics" (i.e., global lightnings) for the high frequency component, or audio magnetotellurics. The National Science Foundation has sponsored the collection of the MT data with the $70 \mathrm{~km}$ grid interval throughout the continental United States as a part of the EarthScope project (Schultz, 2010); this data set is publicly available.

\section{Geologic constraints}

Potential fields and electromagnetic methods are known to have a nonunique solution (e.g., Nettleton, 1971; Dell'Aversana, 2007; Hinze et al., 2013). This is certainly a true statement if no other information about the subsurface model is available. In reality, there is always some a priori information about the modeled subsurface that can be used to 
constrain either physical properties of subsurface rocks or the geometries (depth and thicknesses of the modeled layers). Seismic data are often used to constrain subsurface architecture (with some uncertainties), while seismic velocities derived from refractions (also with uncertainties) serve as proxies for lithologies. Other typical geologic constraints include the information from well logs (physical properties of subsurface rocks and thicknesses of individual formations), surface and outcrop geologic observations (such as lithologies and structures), stratigraphic information, known tectonic features, and/or inferred structures, etc. If no well data are available, the physical properties may be constrained by published values for different lithologies (such as in Schön, 2015). The thicknesses of sedimentary cover and of the crystalline crust can be determined from a global CRUST1.0 model (Laske et al., 2013) and used to constrain the depths to the basement and Moho.

Overall, all available a priori information about the modeled subsurface should be included in the analysis. Once the model (i.e., the set of subsurface layers with assigned physical properties) is developed, the expected geophysical response is calculated and compared with the observed one. The book of Hinze et al. (2013) includes the CD with the basic software available to develop simple subsurface models and compute the response of multiple geophysical methods.

\section{Case studies presented in this special section}

\section{Resolving uncertainties in deep structures mapped from seismic}

In general, the interpretations derived from all geophysical methods have some degree of uncertainty, but the range of that uncertainty varies for different methods at different depths and geometries. The seismic methods are traditionally viewed as the most reliable ones, i.e., " I can see this reflection!," but even the structures interpreted from strong, coherent seismic reflections (i.e., associated with a sharp contrast in acoustic impedance) have some structural ambiguities, especially in their depth, due to uncertainties in seismic velocities used to process the seismic section, particularly during the depth migration (e.g., Fomel and Landa, 2014). The integration with nonseismic methods aims to decrease these ambiguities, although in some cases such integration results in an alternative interpretation of seismic data. In this special section, we present the case study of Grauch et al. that integrates multiple types of geophysical data over the North American Midcontinent Rift. The modeling is based on the old seismic line crossing the northern part of the rift system. The previous interpretation of that seismic suggested that the rift is bounded by a reverse fault. This fault was originally a rift-related normal fault that was structurally inverted during the postrift compressional event. However, the joint analysis of multiple data sets suggests that the fault is best modeled as a normal fault, thus reverting the overall understanding of the extent of the postrift compressional event.

\section{Mapping beneath complex overburden}

It is well known that seismic imaging beneath complex and highly heterogeneous overburden, such as evaporites, volcanic sills/dikes, or highly folded/faulted strata, is dramatically challenged due to an evident complexity of seismic velocities within that overburden (Ravaut et al., 2002; Alumbaugh et al., 2013; Colombo et al., 2014; Filina et al., 2015; Price 
et al., 2015). Here is another application of integrated nonseismic geophysical methods that can help to constrain overburden structures, thus improving the quality of seismic image beneath. The case study of Yang et al. uses the integrated multigeophysical analysis of gravity, MT, and seismic data in the Dayangshu Basin in northeast China to improve the structural imaging of the basin beneath the basin-wide volcanic layer. The workflow developed in that case study represents a low-cost exploration tool that produces valuable data for assessing oil and gas resources in the basin.

In another case study, $\mathrm{Xu}$ et al. present a joint interpretation of gravity, magnetic, seismic, and well data to generate a 3D quasi-geology model and image volcanic units in the Junggar Basin of northwestern China. The integrated study was able to map four major volcanic units throughout the basin and provide more reliable vertical and lateral distribution of volcanic rocks.

\section{Joint 3D inversions of potential fields}

When no seismic constraints are available, the joint analysis of gravity and magnetic data can yield valuable geologic results. This section includes a case study of Sun et al. that tests the value of the separate inversions of magnetic data and gravity gradients versus their joint inversion over the intrusion complex in northeast Iowa and at the southeast Minnesota border. As a result, 3D volumes of density contrast and magnetic susceptibilities are derived. The subsequent geology differentiation allowed for the identification of 10 geologic units, four of which were previously unknown. The resultant 3D quasi-geology model for a Precambrian basement allowed for a better understanding of the geology of that region.

Another case study, Astic et al., images the DO-27 diamondiferous kimberlite pipe located in the Northwest Territories of Canada by joint inversion of gravity and magnetic data along with petrophysical information about the trend of density with depth and the magnetic remanence. As a result, a 3D geologic model of the pipe was developed that distinguishes between the two documented facies and identifies a third type.

\section{Integration toward tectonic reconstruction}

Magnetic data over the oceanic domain are often used to constrain the age and rate of the oceanic spreading (Müller et al., 2008). The distinct magnetic anomalies, such as the wellknown East Coast Magnetic Anomaly of North America or the West Africa Coast Magnetic Anomaly, can also provide the structural framework for the tectonic reconstruction of the Atlantic Ocean in between (e.g., Lundin et al., 2018). Minguez et al. present an analysis from the Gulf of Mexico that offers a new perspective on the tectonic history of the basin based on the joint analysis of gravity, magnetic, and seismic data. Moreover, the authors describe the algorithm of releveling public domain magnetic data of Bankey et al. (2002) that removes multiple artifacts related to individual marine magnetic surveys; the resultant cleaned-up magnetic grid for the offshore Gulf of Mexico is available as supplemental material to this paper. In addition, the digital version of the tectonic reconstruction model for the Gulf of Mexico presented in this paper is also available for download. 


\section{Application of the time-lapse gravity}

Time-lapse gravity compares the gravity surveys acquired over the same study region with some time intervals. With care, the differences between gravity measurements at two different times can be attributed to the density changes in the subsurface that occurred over the time period between the consequent surveys. This methodology is particularly useful to monitor reservoir development and depletion. Balza and Li present a case study that successfully integrates timelapse gravity, water and gas production, and geologic structural data through a gravity inversion. The resultant density contrast models better delineate the regions of the reservoir with increased water influx and allow for improving the porosity estimation throughout the reservoir.

\section{Integration with electromagnetic methods}

In this section, we present two case studies illustrating the value of integration with EM methods that lead to a more confident interpretation of seismic data. The contributions for this section take advantage of joint inversion techniques using cross-gradient model regularization (e.g., Gallardo and Meju, 2004) to constrain 3D CSEM and MT inversion results.

Karpiah et al. describe a 3D anisotropic CSEM and MT joint inversion in the Dangerous Grounds, South China Sea region. The anisotropic joint inversion for vertical and horizontal resistivity is obtained by imposing boundary-shape similarity conditions to the inverted parameters using cross-gradient minimization. The study allowed for mapping the basement, as well as deriving the crustal thickness. The EM derived basement coincident with the resistivity gradients maxima matches the acoustic basement from the seismic survey.

Another case study, Mackie et al. describe a method to extract structural information from seismic reflection volumes via a coherence-weighted structure tensor to guide the inversion of CSEM and MT data. The structural similarity between seismic and resistivity is achieved by cross-gradient regularization of seismically derived gradient fields and the inversion resistivity model. This integration offers a way to achieve automatic structural consistency with geologic and other collocated geophysical measurements.

\section{Conclusion}

This special section is organized by the Gravity and Magnetic committee following the workshop during the SEG 2018 Annual International Meeting. The workshop concluded that the integration with nonseismic methods is generally undervalued in the geoscience community. This special section presents nine case studies demonstrating how the integration with gravity, magnetics, and electromagnetic methods can improve the subsurface model, decrease the uncertainty of interpretation, and even provide a new perspective on the geologic evolution of the study region. We hope that this special section will boost interest in the integrated geophysical imaging in the general geoscience community and eventually will promote the integrative approach in all aspects of geophysical and geologic exploration.

Acknowledgments - The editors are extremely grateful to the members of the Gravity and Magnetics community for submitting the manuscripts to this special section and for serving as reviewers. 
We are particularly thankful to E. Biegert, M. Rauch, L. McGregor, E. Turkoglu, T. Blanchard, and S. Goussev for reviewing multiple papers and for providing detailed recommendations and constructive criticism to the authors despite a tight schedule. We would like to thank the wonderful SEG staff that worked with us on this special section and were extremely helpful and accommodating. Thank you!

\section{References}

Alumbaugh, D., M. Hoversten, J. Stefani, and C. Thacher, 2013, A 3D model study to investigate EM imaging of sub-basalt structures in a deepwater environment: 83rd Annual International Meeting, SEG, Expanded Abstracts, 765-769, doi: 10.1190/segam2013-0251.1.

Bankey, V., A. Cuevas, D. Daniels, C. A. Finn, I. Hernandez, P. Hill, R. Kucks, W. Miles, M. Pilkington, C. Roberts, and W. Roest, 2002, Digital data grids for the magnetic anomaly map of North America (No. 2002-414).

Bedrosian, P. A., 2007, MT+, integrating magnetotellurics to determine earth structure, physical state, and processes: Surveys in Geophysics, 28, 121-167, doi: 10.1007/s10712-007-9019-6.

Colombo, D., G. McNeice, N. Raterman, M. Zinger, D. Rovetta, and E. Sandoval Curiel, 2014, Exploration beyond seismic: The role of electromagnetics and gravity gradiometry in deep water subsalt plays of the Red Sea: Interpretation, 2, no. 3, SH33-SH53, doi: 10.1190/INT-2013-0149.1.

Constable, S., 2010, Ten years of marine CSEM for hydrocarbon exploration: Geophysics, 75, no. 5, 75A67-75A81, doi: 10.1190/1.3483451.

Dell' Aversana, P., 2007, Marine CSEM data interpretation: Pitfalls and possible solutions: The Leading Edge, 26, 686-691, doi: 10.1190/1.2748482.

Filina, I., E. K. Biegert, L. Sander, V. Tschirhart, N. Bundalo, and C. Schiek-Stewart, 2019, Integrated imaging: A powerful but undervalued tool: The Leading Edge, 38, 720-724, doi: 10.1190/tle380 90720.1.

Filina, I., N. Delebo, G. Mohapatra, C. Coble, G. Harris, J. Layman, M. Strickler, and J. P. Blangy, 2015, Integration of seismic and gravity data-A case study from the western Gulf of Mexico: Interpretation, 3, no. 4, SAC99-SAC106, doi: 10.1190/INT-2015-0050.1.

Fomel, S., and E. Landa, 2014, Structural uncertainty of time-migrated seismic images: Journal of Applied Geophysics, 101, 27-30, doi: 10.1016/j.jappgeo.2013.11.010.

Gallardo, L. A., and M. A. Meju, 2004, Joint two-dimensional DC resistivity and seismic travel time inversion with cross-gradients constraints: Journal of Geophysical Research, Solid Earth, 109, B03311, doi: 10.1029/2003JB002716.

Hemant, K., E. Thébault, M. Mandea, D. Ravat, and S. Maus, 2007, Magnetic anomaly map of the world: Merging satellite, airborne, marine and ground-based magnetic data sets: Earth and Planetary Science Letters, 260, 56-71, doi: 10.1016/j.epsl.2007.05.040.

Hinze, W. J., R. R. Von Frese, and A. H. Saad, 2013, Gravity and magnetic exploration: Principles, practices, and applications: Cambridge University Press.

Kucks, R. P., 1999, Bouguer gravity anomaly data grid for the conterminous US: US Geological Survey Digital Data Series DDS-9.

Laske, G., G. Masters, Z. Ma, and M. Pasyanos, 2013, Update on CRUST1.0-A 1-degree global model of Earth's crust: Geophysical Research Abstracts, 15, 2658.

Li, C. F., Y. Lu, and J. Wang, 2017, A global reference model of Curie-point depths based on EMAG2: Scientific Reports, 7, 45129, doi: 10.1038/srep45129. 
Lundin, E. R., A. G. Doré, and T. F. Redfield, 2018, Magmatism and extension rates at rifted margins: Petroleum Geoscience, 24, 379-392, doi: 10.1144/petgeo2016-158.

Meyer, B., R. Saltus, and A. Chulliat, 2017, EMAG2 Version 3-Update of a two arc-minute global magnetic anomaly grid: EGUGA, 10614.

Müller, R. D., M. Sdrolias, C. Gaina, and W. R. Roest, 2008, Age, spreading rates, and spreading asymmetry of the world's ocean crust: Geochemistry, Geophysics, Geosystems, 9, Q04006, doi: 10.1029/2007GC001743.

Nettleton, L. L., 1971, Elementary gravity and magnetics for geologists and seismologists: SEG.

Price, A., M. Flouret, S. Rouyer, and C. Ayong-Mba, 2015, Sub-salt modelling in 3D-integration of seismic, well and gravity data validated by drilling: 77th Annual International Conference and Exhibition, EAGE, Extended Abstracts, doi: 10.3997/2214-4609.201412913.

Rajaram, M., 2007, Depth to Curie temperature, in D. Gubbins and E. Herrero-Bervera, eds., Encyclopedia of geomagnetism and paleomagnetism: Springer.

Ravaut, P., S. Russell, P. Mallard, J. F. Ballard, D. Watts, R. Mackie, and S. Hallinan, 2002, 3D Magnetotellurics for imaging a Devonian reservoir (Huamampampa) in the southern Sub-Andean basin of Bolivia: 72nd Annual International Meeting, SEG, Expanded Abstracts, 2417-2421, doi: 10.1190/ 1.1817205.

Sandwell, D. T., R. D. Müller, W. H. Smith, E. Garcia, and R. Francis, 2014, New global marine gravity model from CryoSat-2 and Jason-1 reveals buried tectonic structure: Science, 346, no. 6205, 65-67.

Schön, J. H., 2015, Physical properties of rocks: Fundamentals and principles of petrophysics: Elsevier.

Schultz, A., 2010, EMScope: A continental scale magnetotelluric observatory and data discovery resource: Data Science Journal, 8, IGY6-IGY20. 